\title{
Clinical and endoscopic findings of children hospitalized in Qa'em Hospital of Mashhad due to caustic ingestion (2011-2013)
}

Alireza Sabzevari ${ }^{1}$, Gholamali Maamouri ${ }^{1}$, Mohammad Ali Kiani ${ }^{1}$, Masumeh Saeidi ${ }^{2}$, Hamidreza Kianifar ${ }^{1}$, Seyed Ali Jafari ${ }^{1}$, Hamid Ahanchian ${ }^{1}$, Lida Jarahi ${ }^{1}$, Elham Roudi ${ }^{2}$, Mohammad Sharafkhani ${ }^{3}$

${ }^{1}$ Faculty of Medicine, Mashhad University of Medical Sciences, Mashhad, Iran

${ }^{2}$ Student Research Committee, Faculty of Medicine, Mashhad University of Medical Sciences, Mashhad, Iran

${ }^{3}$ Student Research Committee, School of Nursing and Midwifery, Mashhad University of Medical Sciences, Mashhad, Iran

\section{Type of article: Original}

\begin{abstract}
Introduction: One of the leading causes of damage to the gastrointestinal tract in children is caustic ingestion which is sometimes life-threatening. The most reliable way to study the severity and extent of damage is endoscopy, which can be harmless in terms of time and technique. The aim of this study was to investigate, evaluate and compare clinical findings and endoscopic results of caustic ingestion.

Methods: This retrospective cross-sectional study was conducted on the records of children diagnosed with caustic ingestion, and hospitalized in Qa'em Hospital of Mashhad from March 2011 to December 2013. Intended data were extracted from patients' records and in case of any ambiguity, it was removed by phone call. Obtained data were analyzed using SPSS 11.5 and chi-square test.

Results: Of 54 patients, there were 36 cases of burn with acidic substance and 16 cases of burn with alkaline. The highest value was related to caustics related to acid batteries $(31.5 \%)$ and in $77.5 \%$ of cases the container of caustic agent was not standard. In endoscopic results, 50 patients out of 54, had esophagus burn such that in 6 cases it was grade I burn, in 15 cases grade IIa, 27 cases with grade IIb and 2 cases with Grade IIIa burn. In addition, mild erythema of stomach in 6 cases, average erythema in 5 cases, mild ulcer in 15 cases, average ulcer in 5 cases and 3 cases with severe ulcer were reported. There was no significant relation between clinical findings and endoscopic results $(\mathrm{p}=0.68)$.

Conclusion: Since caustic ingestion can be regarded as a life-threatening factor for children, the importance of observing precautions in the storage of caustics and the role of training and adequate attention of parents to this issue to prevent such accidents is clear.
\end{abstract}

Keywords: Caustics; Endoscopy; Children

\section{Introduction}

Accidental caustic ingestion is the most common cause of esophagus injury, a life-threatening factor and a general concern for physicians in the neonatal emergency department. This damage is mainly seen among 1-3 year-old children, and boys encompass $50-62 \%$ of cases. Unfortunately, most of these caustics have been easily available to children as cosmetics and cleansing agents (1-3). In 2014, 2.1 million cases of human exposure to toxic agents was reported in the U.S., $48 \%$ of which was related to 5 -year-olds and smaller children. Domestic cleansers especially bleach were accountable for $71 \%$ of cases. Alkali cases are more common compared to acids. This mostly happens in developing and undeveloped countries due to easier access to these caustics, and it is the leading cause of children's referral to hospitals. Its clinical signs vary from esophagus burn to esophageal transplant $(1,4,5)$. Although, in most cases this happens accidentally due to parents' negligence and not observing required precautions, some cases of child abuse are also reported $(1,5)$. Accidental ingestion of caustics may damage lips, oropharynx and upper airway $(1,6)$. Short-term complications include bleeding, shock, airway edema, esophagus perforation, and

\section{Corresponding author:}

Dr. Mahammad Ali Kiani, Faculty of Medicine, Mashhad University of Medical Sciences, Mashhad, Iran.

Tel: +98.38412069, Fax:+98.38410137, Email: Kianima@mums.ac.ir

Received: April 12, 2016, Accepted: June 08, 2016, Published: April 2017

iThenticate screening: July 20, 2016, English editing: January 16, 2017, Quality control: March 12, 2017

(C) 2017 The Authors. This is an open access article under the terms of the Creative Commons Attribution-NonCommercialNoDerivs License, which permits use and distribution in any medium, provided the original work is properly cited, the use is non-commercial and no modifications or adaptations are made. 
death, and long-term complications include tightness in various parts of the gastrointestinal tract, tracheoesophageal fistula, shortening of esophagus, incompetent lower esophageal sphincter and increased esophageal carcinoma in children (5). The nature of damage is determined using factors like the intended factor, dosage, $\mathrm{pH}$, concentration and duration of tissue exposure. Caustics damage tissues via chemical reactions. Typically, acids with a $\mathrm{pH}$ lower than 3 and alkalis with a $\mathrm{pH}$ over 11 create many concerns in damage $(1,4,5)$. Different variables including economic, social, and educational factors, namely parent's education particularly mothers, family income, working mother, and mother's age can affect the prevalence of these accidents (4). The general plan is different for treatment of caustic ingestion, there is no census and there are different protocols available. Initial steps in management of patients with caustic ingestion include supportive care and close observation of the disease with emphasis on prevention of vomiting, choking and aspiration. Upper endoscopy is recommended for most patients with a definitive history of caustic ingestion, ideally within 24 hours. Neutralizing or diluting the caustic, using active coal or gastric lavage is not recommended due to more possible damages $(1,5)$. The aim of this study was to evaluate and compare clinical findings and endoscopic results of caustic ingestion in children referring Qa'em Hospital of Mashhad.

\section{Material and Methods}

This cross-sectional study was conducted within 33 months, from March 2011 to the end of December 2013, on the records of 54 children referred to Qa'em Hospital affiliated to Mashhad University of Medical Sciences, who were hospitalized and received endoscopy in that hospital within mentioned period. Collected personal data included age, gender, location, place of storing caustics, parents' education, clinical signs (vomiting, stomachache, swelling of the lips, hematemesis), endoscopic findings (involvement of the stomach in terms of burn grade and stomach inclusion) the caustic (nature and type), data related to hospitalization and treatment of the patient according to the designed checklist. All endoscopies were conducted with the same device by 3 gastroenterologist specialists, and esophageal mucosal lesions were reported according to Zargar categorization (7). Patients who were not willing to conduct endoscopy for any reason, were excluded from the study. To observe ethical considerations, results were published anonymously. Obtained data were analyzed using SPSS version 11.5 (SPSS Inc., Chicago, Illinois, USA) and Chi square test.

\section{Results}

Of 54 children under study, 59.3\% were boys (32) and 40.7\% were girls (22). Age distribution of these children was $34 \%$ (18) from birth to 2-years old, 34\% (18) 2-4 years old, $17 \%$ (9) $4-6$ years old and $15 \%$ (8) children over 6 years old. Of these children, $64.8 \%$ (35) were living in urban areas and $35.2 \%(19)$ in rural areas. The place of storing caustics was: $25 \%(10)$ in the yard and $18 \%$ (7) in other places (car trunk, in the store, etc.) $15 \%(6)$ in the kitchen, $15 \%$ (6) in spaces inside the house, $12 \%$ (5) inside the bathroom and $16 \%$ (6) on the roof, cellar, stairs or greenhouse. Nonstandard cases were those that the caustic was stored in bottle, water bottle, drinks bottle and lidless or other containers, and of 40 cases completed using a phone call, $22.5 \%(9)$ were reported to be standard and $77.5 \%$ (31) were nonstandard. In terms of the type of caustic, 17 cases were acid battery, 11 cases pipe opener, 10 cases were descaling solution, 6 cases citric acid and other agents including 5 cases of (acid, potassium, permanganate), 2 unknown cases, and 1 case for gas cleaner, vegetable disinfectants and bleach. In terms of the nature of caustic, $69.2 \%$ were reported to be acidic (36) and 30.8\% were alkali (16). In terms of the physical form of caustics, $92.5 \%$ of cases were liquid (49), 3.8\% were powder (2) and 3.8\% were solid substances swallowed by children. Antibiotics had been used to treat $63 \%$ of children (34) and they were not administered for $37 \%$ of them (20). In terms of education, $57 \%$ of fathers and $52 \%$ of mothers were under diploma. In endoscopy results of 50 patients out of 54 patients of esophageal burn in this study, grade I lesion was reported in $11.1 \%$ of children and grade II and more burn was reported in $81.5 \%$ of them. In stomach endoscopy, $11.1 \%$ of children had mild erythema, $9.3 \%$ average erythema, $27.8 \%$ mild ulcer, $9.3 \%$ average ulcer and $5.6 \%$ had severe ulcer.

\section{Discussion}

In this study, more poisoning occurred among urban boys. In other studies, poisoning of boys is reported more frequently $(4,6,8)$. In addition, poisoning in cases when caustics were stored in the yard was reported more frequently. Damage due to caustics is more common among children than other age groups. Parents' negligence relative to caustics and chemicals that are stored and used as domestic compounds have resulted in accidental and easy access for children under 5 year-old to these substances, and they result in severe damage and major complications in gastrointestinal tract, especially in esophagus $(4,9)$. Unfortunately, in developed and developing countries, despite training programs and regulations for limiting access to caustics, caustic ingestion is considered as a major health issue (10). In this study, most caustic ingestions in children were as liquid substance.. This can be due 
to the fact that most domestic or industrial acids and alkalis namely pipe openers, car battery water, industrial detergents, bleaches and other detergents are in the form of liquid. These liquid substances create diffuse burn, and solid substances create local burn (6). In this study, $69.2 \%$ of cases reported were acid ingestion. In another study conducted in Tabriz, the most common caustic has been reported to be alkali (84.3\%) (6). Studies that report caustic ingestion with alkalis occur mainly in developed countries and acid ingestion has mainly occurred in developing nations (4). In endoscopic results of 50 patients out of 54 patients of esophagus burn in this study, grade I lesion was reported among $11.1 \%$ of children and grade II and more among $81.5 \%$ of children; while in the study conducted in Tabriz, 37.2\% of children suffered from grade I burn and the other $62.8 \%$ grade II and higher lesions (6). Since in this study in $77.5 \%$ of cases reported, the caustic has been stored in nonstandard container including drink bottle, water bottle or other containers not intended for this purpose, it is clearly required that parents pay more attention to storing these caustics in a safe container and place out of reach of children.

\section{Conclusions}

In summary, findings of this study showed that more poisoning with liquid caustics has occurred among urban boys. The functional importance of these findings is that caustic ingestion by children can be prevented, and training via various media including television, radio and newspaper plays and important role in this regard; therefore, adequate and effective training is recommended for this purpose. It is suggested to caustic manufacturers to design special safe containers for these substances in a form that cannot be easily accessed by children. Obviously, it is the parents' responsibility to store these dangerous agents out of reach of children, in a safe place to prevent serious damage or even death in this age group. Conducting a complementary study on caustic ingestion in various regions of Iran and comparing results to plan suitable programs for prevention, can be a suitable route for later studies.

\section{Acknowledgments:}

Authors of this study appreciate research deputy of Mashhad University of Medical Sciences for their financial support of this study. This paper is extracted from the results of $\mathrm{PhD}$ dissertation of occupational medicine, issue number 920391.

\section{Conflict of Interest:}

There is no conflict of interest to be declared.

\section{Authors' contributions:}

All authors contributed to this project and article equally. All authors read and approved the final manuscript.

\section{References:}

1) Fishman DS. Caustic esophageal injury in children. 2016. Available from: http://www.uptodate.com/contents/caustic-esophageal-injury-in-children.

2) Cakmak M, Göllü G, Boybeyi Ö, Küçük G, Sertçelik M, Günal YD, et al. Cognitive and behavioral characteristics of children with caustic ingestion. J Pediatr Surg. 2015; 50(4): 540-2. doi: 10.1016/j.jpedsurg.2014.10.052. PMID: 25840059.

3) Weigert A, Black A. Caustic ingestion in children. Continuing Education in Anaesthesia. Critical Care \& Pain. 2005; 5(1): 5-8. doi: 10.1093/bjaceaccp/mki007.

4) Sánchez-Ramírez CA, Larrosa-Haro A, Vásquez-Garibay EM, Macías-Rosales R. Socio-demographic factors associated with caustic substance ingestion in children and adolescents. International journal of pediatric otorhinolaryngology. 2012; 76(2): 253-6. doi: 10.1016/j.ijporl.2011.11.015. PMID: 22188823.

5) Lupa M, Magne J, Guarisco JL, Amedee R. Update on the diagnosis and treatment of caustic ingestion. Ochsner J. 2009; 9(2): 54-9. PMID: 21603414 , PMCID: PMC3096249.

6) Rafeey M, Shoaran M, Eghbali E. Clinical characteristics and complications in oral caustic ingestion in children. Urmia medical journal. 2009; 20(2): 132-6.

7) Cheng HT, Cheng CL, Lin CH, Tang JH, Chu YY, Liu NJ, et al. Caustic ingestion in adults: the role of endoscopic classification in predicting outcome. BMC gastroenterology. 2008; 8: 31. doi: 10.1186/1471230X-8-31. PMID: 18655708, PMCID: PMC2533005.

8) Hamza AF, Abdelhay S, Sherif H, Hasan T, Soliman H, Kabesh A, et al. Caustic esophageal strictures in children: 30 years' experience. J Pediatr Surg. 2003; 38(6): 828-33. doi: 10.1016/S0022-3468(03)00105-2. PMID: 12778375.

9) Walker WA. Pediatric gastrointestinal disease. 4 ed. Ontario, BC Decker. 2004; Pp: 464-80.

10) Riffat F, Cheng A. Pediatric caustic ingestion: 50 consecutive cases and a review of the literature. Dis Esophagus. 2009; 22(1): 89-94. doi: 10.1111/j.1442-2050.2008.00867.x. PMID: 8847446. 